\title{
The Effect of Radiation on Mechanical Properties of Parts Made of Polymer Composites
}

\author{
František Greškovič ${ }^{1, *}$, Ludmila Dulebová ${ }^{2}$ \\ ${ }^{1 *}$ Faculty of Mechanical Engineering, Technical University of Košice, Department of Automobile Production, Košice, Slovakia \\ ${ }^{2}$ Faculty of Mechanical Engineering, Technical University of Košice, Department of Engineering Technologies and Materials, Košice, Slovakia
}

\begin{abstract}
The article deals by the application area of radiation crosslinking of plastics, which follows after the injection moulding. The main objective of the presented article is the research of influence irradiation dosage on mechanical properties of materials: PP unfilled and PP filled by $25 \%$ of glass fibres. Mechanical properties (tensile strength, modulus, bending stress and impact strength by Charpy test) were examined in dependence on absorbed dose of the $\beta$ electron radiation on various conditions and were compared with non-irradiated samples.
\end{abstract}

Keywords: polypropylene; irradiation; radiation dose; mechanical properties.

\section{Introduction}

Cross-linking of plastics is a term that we meet in many areas and outside the field of technology too. Radiation cross-linking basically improves plastics in three different ways: it gives them better thermal stability, better abrasion resistance and better resistance to chemical and mechanical influences [1], [2].

The cross-linking of plastics is a chemical process, in which particular molecules of plastics are connected together. In an ideal case, all the molecules will be integrated into the above mentioned grid and the process can be activated by radiation in case of many plastics [3].

Cross linking will be initiated by irradiating with high energy electron beams or gamma rays. The energy resulting from the irradiation is absorbed by the plastic. The main difference between beta and gamma rays lies in their abilities of penetrating the irradiated material [4]. Gamma rays have a high penetration capacity. The penetration capacity of electron rays depends on the energy of the accelerated electrons. The process takes place at room temperature and under normal pressure. Irradiation takes place after the molding process [5]. The most important properties of cross-linking systems are tensibility and elasticity, which also remain under long-time temperature and mechanical loading.

The majority of industrial applications of radiation processing are cross-linking of wire and cable insulations, tube, heat shrink cables, composites, molded products for automotive and electrical industry etc. [6], [7].

The properties of a composite filled with element filler depend on the physical properties of components (matrix, filler). The coherence of the matrix with the filler has a significant influence on the resultant transmission of stresses on reinforcement and the resultant mechanical properties [8].

The radiation technology of beta or gamma rays is used to achieve joining of 
the matrix structure with the reinforcement, which increases the strength, as can be seen in the Figure 1 and Figure 2.

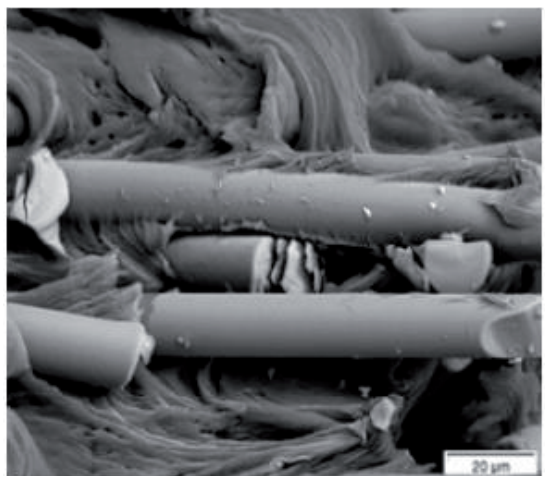

Fig. 1: Structure of unirradiated material.

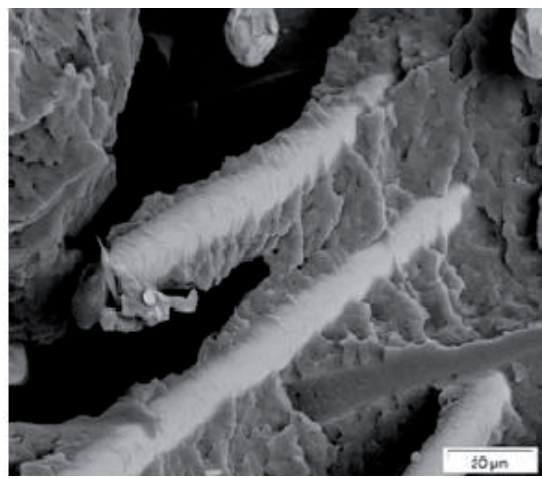

Fig. 2: Structure of irradiated material.

Evaluation of composite structure is usually done in fracture area in tensile test. It is realized by REM RE-Detector with given magnification. Presented structure in figure above is for material filled with glass short fibres PA6 GF30. Structure is irradiated by dose of $100 \mathrm{kGy}$. Microscopic analysis discovered higher adhesion of polymer matrix to glass fibres resulting from irradiation, which improves the mechanical properties [9].

\section{Experimental procedure}

Material tested in this work was PTS-Crealen EP-2300L1-M800 - unfilled PP and PTS-Crealen EP8G5HS*M0083 - PP filled by $25 \%$ of glass fibres. Commercial polypropylenes have up to $95 \%$ isotactic content, which means that pendant methyl groups are almost all on the same side of the chain. When polypropylene is exposed to ionizing radiation, free radicals are formed and these cause chemical changes [8].
Test samples enriched by cross-linking agent and test samples without cross-linking agent have been produced by injection moulding technology and were used injection mould with replaceable mould boards. Testing samples were prepared in an injection moulding machine DEMAGERGOETECH 50 - 200. The test samples were controlled after injection molding process and after the conditioning time. Produced test samples were irradiated by $\beta$ electron radiation in the company BGS Beta-Gamma-Service GmbH\&Co, Saal a.d. Donau, Germany, by irradiation dose 15 kGy and 33 kGy. After irradiation were carried out selected tests namely tensile test, bending test and Charpy impact test. Individual tests of test samples were made in the environment - standard ambient (in $23^{\circ} \mathrm{C}$ ) and ambient with temperature of $-35^{\circ} \mathrm{C}$ (Charpy impact test). Radiation influences on mechanical properties of the test samples were observed [10].

\section{Discussion and results \\ 3.1 Tensile test}

Tensile test was realized according to STN EN ISO 527-1, 527-2 standard in surrounding temperature of $23^{\circ} \mathrm{C}$ on testing machine ZWICK 1456 and were used samples type $1 \mathrm{~A}$ for testing. The graphic dependence of the measured average values of the tensile test is shown in Figure 3 to Figure 5.
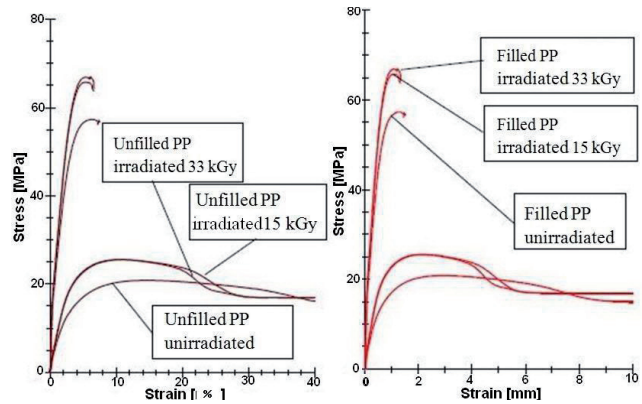

Fig. 3: Tensile curve of unfilled PP and filled PP.

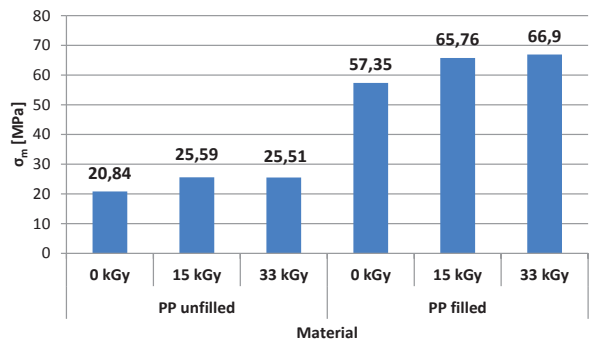

Fig. 4: Tensile strength of materials PP after tensile test. 


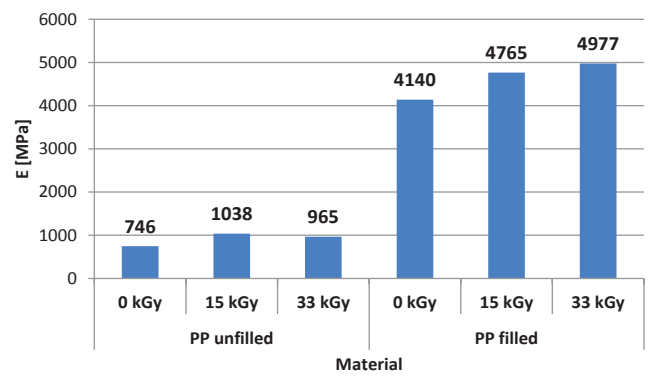

Fig. 5: Young's modulus of materials PP after tensile test.

Irradiation of test samples causes changes in the ultimate strength and Young's modulus of filled and unfilled $\mathrm{PP}$, the changes reached relatively considerable values.

\subsection{Pretreatment of base material}

Radiation of $15 \mathrm{kGy}$ and $33 \mathrm{kGy}$ at ambient temperature improves the flexural strength and Young's modulus in filled and unfilled PP. Failure of material in unfilled samples does not occur. The amount of radiation in this temperature has a minor influence on the flexural strength, in favour of 15 kGy dose of unfilled PP compared to 33 kGy dose. Comparison of flexural strength of filled and unfilled PP shows Figure 6 and Figure 7, where is shown considerable improvement of properties by filling the PP.

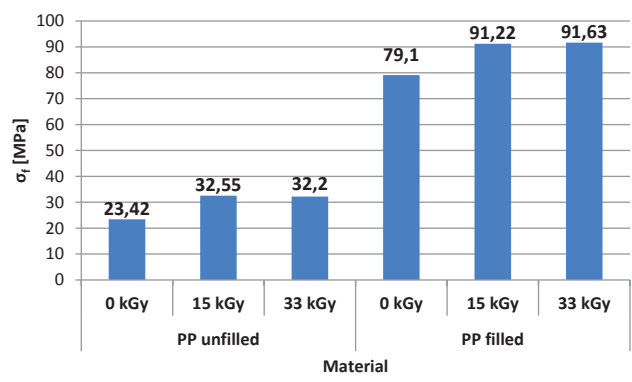

Fig. 6: Flexural strength of materials PP after bending test.

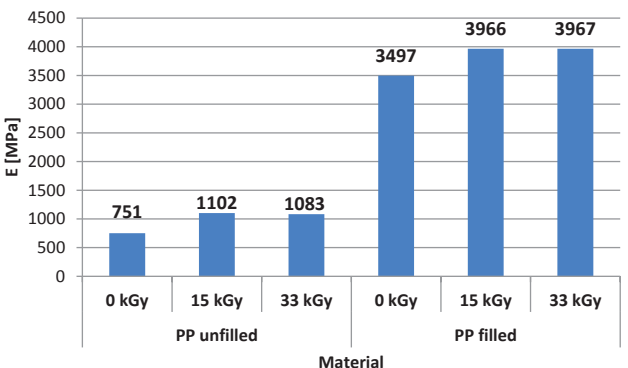

Fig. 7: Comparison of Young's modulus of PP after bending test.

\subsection{Impact strength}

Measurement was carried out on Charpy hammer ZWICK 5113 Pendulum Impact Tester in surrounding temperature of $23^{\circ} \mathrm{C}$ and temperature of $-35^{\circ} \mathrm{C}$, hammer $5 \mathrm{~J}$ was used. For evaluation of impact resistance of plastics was made according to STN EN ISO 179 - 1 standard. It was tested in 10 samples of each type of materials. The test results are shown in Figure 8 and Figure 9.

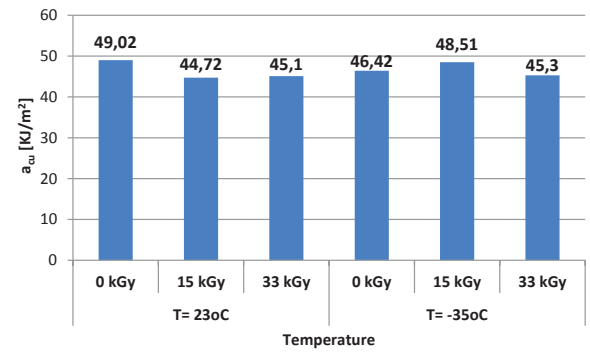

Fig. 8: Comparison of impact strength of filled $P P$ in various temperatures.

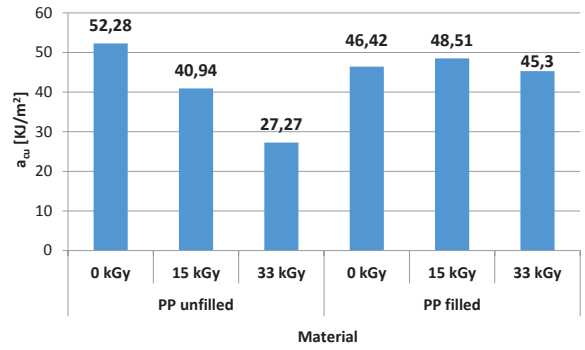

Fig. 9: Comparison of impact strength of PP for the temperature of $-35^{\circ} \mathrm{C}$.

In the ambient temperature in all the unfilled PP no puncture occurs. Irradiation of filled PP decreases the impact strength in comparison with unirradiated filled PP. The dose rate of irradiation does not matter. In testing the samples at the temperature of $-35^{\circ} \mathrm{C}$, punctures occur in all unfilled and filled materials. The impact strength is decreased. When comparing unfilled and filled samples, decreasing of toughness occurs in unirradiated filled material.

In irradiation of $15 \mathrm{kGy}$ and $33 \mathrm{kGy}$ toughness increases in filled materials. The result of toughness comparison of filled PP material is that in unirradiated PP material measured in $-35^{\circ} \mathrm{C}$ was observed decreased toughness compared to measurement in the ambient temperature. The radiation of $15 \mathrm{kGy}$ in $-35^{\circ} \mathrm{C}$ increases the toughness compared to the measurement in the ambient temperature. In the radiation of $33 \mathrm{kGy}$, the toughness does not change 
in relation to temperature.

\section{Conclusion}

On the basis of the experimental results could be formulated these results:

- The tensile test showed that irradiation by $15 \mathrm{kGy}$ and $33 \mathrm{kGy}$ at the ambient temperature of $23^{\circ} \mathrm{C}$ increases the ultimate strength in both filled and unfilled PP by $15-20 \%$. The highest values of both ultimate strength and module of elasticity were reached after irradiation by $33 k G y$.

- The bending test showed that irradiations by $15 \mathrm{kGy}$ and $33 \mathrm{kGy}$ at the ambient temperature of $23^{\circ} \mathrm{C}$ improve the ultimate strength of both filled and unfilled PP by approximately 25 to 30\%.

The comparison of filled and unfilled materials showed that the filling increases the material resistance by approximately 400\%. The influence of irradiation is less significant-it increases the resistance by approximately 12\%. In the impact strength test of unfilled PP there occurred no failure in samples, in contrast to filled PP.

- The plasticity of unfilled PP was higher, that is why there was no failure in samples. Such samples cannot be evaluated according to the standard. Irradiation cross-linking typically aims from the surface of the product inwards and occurs exclusively in amorphous areas of the plastic.

- The influence of irradiation has only a little influence on the melting temperature. It ranges within $1-2^{\circ} \mathrm{C}$, i.e. the influence is unimportant.

Obtained knowledge in this paper are only parts of the general problem of possible applications of plastics cross-linking. For example as the automotive industry using a wide range of plastics, it would be suitable to extend the experiments to other materials and monitoring of other properties such as bonding - gluing and coating (adhesion improvement), the influence on welding property and thermal analysis, recycling of cross-linked plastics.

\section{Acknowledgements}

This work was supported by the project VEGA 1/0600/13 granted by Scientific grant agency VEGA of Ministry of Education, Science, Research and Sport Slovak Republic.

\section{References and Notes}

[1] Brocka, Z. (2006). Strahlenvernetzte Kunststoffe Verarbeitung. Eigenschaften, Anwendung, Springer VDI Verlag, Düsseldorf. 1 - 30 .
[2] Maňas, D. et al. (2008). Improvement of plastic properties Materials Science and Engineering, 32, 2, 69-76.

[3] Zyball, A. (2004). Radiation Processing of Polymers. In: Emerging applications of radiation processing, IAEA-TECDOC-1386, Vienna, pp. 117-125.

[4] Gamma irradiators for radiation processing. International atomic energy agency, Vienna, Austria. (01.03.2016). http:// www-naweb.iaea.org/napc/iachem/Brochure\%20on\%20 gamma\%20irradiators.pdf

[5] Tauzin, B., Hermitte, L. Ponsart, S. (2006). Influence of crosslinking process on rheology of the sodium hyaluronate matrix. European Cells and Materials, 11, 2, 34.

[6] Pucić, I. (2009). Radiation crosslinking and liquid-liquid transitions in unsaturated polyesters. Polimeri, 30, 4, 193 - 204.

[7] Kunstoff Magazin (2009): Hart im Nehmen Strahlenvernetzung für hohe Temperaturen, 46 - 47.

[8] Drobny, J. G. (2010). Radiation Technology for polymers. New York, second edition, 63 - 85.

[9] Gehring J. (2000). With radiation crosslinking of engineering plastics into the next millennium. Radiation Physics and Chemistry, 57, 3, 361-365.

[10] Greškovič, F. et al. (2008). Benefit analysis of cross-linking in processing automotive interior parts made of plastics and the change of their final properties after cross-linking, Contract for work No.44/2008, TU Košice, pp.68.

\section{Biographical notes}

František Greškovič, prof., Ing., CSc., (born in 1956) is a professor at the Technical University of Košice, Faculty of Mechanical Engineering, Institute of Technologies and Management. He graduated from the Faculty of Mechanical engineering in 1980. His research areas are processing and simulation of injection molding, as well as die design in CAD/CAM systems and 30 modelling. He is an author/co-author of 1 monography, 3 textbooks and more than 170 publications in journals and conference proceedings in Slovakia and abroad. Eight papers were registered in Web of Science and SCOPUS. He is co-author of nine patents. He has been involved in several grant projects and research tasks

'Ludmila Dulebová, doc., Ing., PhD., (born in 1961) is associate professor at the Technical University of Košice, Faculty of Mechanical Engineering, Department of Engineering Technologies and Materials. She graduated in 1983 at the VŠT Košice and obtained the PhD. degree (2008) in 23-07-9 Mechanical Engineering Technology and Materials at the Technical University of Košice. Her research areas are processing and simulation of injection molding, as well as testing and analysis of the properties of polymer materials. She is a co-author of one monography and two textbooks. One her paper was registered in Current Contents paper, nineteen papers were registered in Web of Science and SCOPUS. She is co-author of two patents. 